\title{
Mechanisms underlying increased reactivity of pulmonary arteries contralateral to a localized high-flow anastomosis
}

\author{
Sandra Pfister, $\mathrm{PhD},{ }^{\mathrm{a}}$ Lewis Somberg, $\mathrm{MD},{ }^{\mathrm{b}}$ Timothy Lowry, $\mathrm{PhD},{ }^{\mathrm{c}}$ Ying Gao, $\mathrm{MS},{ }^{\mathrm{c}}$ Meetha Medhora, $\mathrm{PhD},{ }^{\mathrm{c}}$ \\ and Elizabeth R. Jacobs, MD, MBA ${ }^{\mathrm{c}}$
}

\begin{abstract}
Objectives: Our model of a systemic-pulmonary shunt exhibits enhanced reactivity of pulmonary arteries contralateral to a localized shunt between the left lower lobe pulmonary artery and aorta relative to those of ipsilateral or control pulmonary arteries 48 hours after anastomosis. We examined the contribution of nitric oxide, cyclooxygenase, lipoxygenase, or cytochrome $\mathrm{P} 450$ production to mediating this enhanced reactivity.
\end{abstract}

Methods: We created a surgical end-to-side anastomosis of the left lower lobe pulmonary artery to the aorta. Forty-eight hours later, we tested tension of pulmonary artery rings from the right and left lower lobes for contraction to the thromboxane mimetic U46619 in the presence of vehicle or inhibitors of nitric oxide synthase, cyclooxygenase, cytochrome P450, or lipoxygenase. Western blots of pulmonary artery homogenates were probed for endothelial nitric oxide synthase or isoforms metabolizing arachidonic acid. Eicosanoid products from intact pulmonary artery rings were detected using labeled arachidonic acid and high-performance liquid chromatography separation.

Results: Enhanced reactivity of unshunted right pulmonary arteries over that of left pulmonary arteries from high-flow hosts was not eliminated by inhibitors of nitric oxide synthase, cyclooxygenase, cytochrome P450. Treatment with 2 different lipoxygenase inhibitors, nordihydroguaiaretic acid and cinnamyl-3,4-dihydroxy- $\alpha$ cyanocinnamate, closed the difference in contractility of shunted and unshunted pulmonary arteries. Pulmonary arteries contralateral to shunts metabolized arachidonic acid to 12-hydroxyeicosatetraenoic acid in greater quantities than analogous pulmonary arteries from the experimental left or control pulmonary arteries.

Conclusions: Forty-eight hours after anastomosis, enhanced reactivity of contralateral pulmonary arteries is attributable in part to increased lipoxygenase products as opposed to nitric oxide or other eicosanoid products.

(J Thorac Cardiovasc Surg 2011;141:425-31)

High flow and pressure are reported to increase or decrease elaboration of both prodilatory and proconstrictive factors in the pulmonary circulation..$^{1-3}$ Variability in these findings has been attributed to differences in the duration of exposure to high flow rates, with the implication that a shift from predominance of provasodilatory to proconstrictive factors occurs at some point after initiation of high flow. The effect of a localized anastomosis on endothelium-derived products of pulmonary arteries not directly exposed to high flow or pressure in vivo has not been examined to our knowledge. We developed a model of localized high flow to the left lower lobe and examined reactivity of pulmonary arteries from ipsilateral and contralateral pulmonary arteries 48 hours later. We

\footnotetext{
From the Departments of Pharmacology \& Toxicology, ${ }^{\mathrm{a}}$ Surgery, ${ }^{\mathrm{b}}$ and Medicine, ${ }^{\mathrm{c}}$ Medical College of Wisconsin, Milwaukee Wis.

Grant support from the National Heart, Lung, and Blood Institute: grants HL068627 and HL-49294 (to E.R.J.).

Disclosures: Authors have nothing to disclose with regard to commercial support

Received for publication Nov 30, 2009; revisions received June 22, 2010; accepted for publication July 5, 2010; available ahead of print Nov 15, 2010.

Address for reprints: Elizabeth R. Jacobs, MD, MBA, Pulmonary and Critical Care Division, Department of Medicine, Medical College of Wisconsin, 9200 W. Wisconsin Ave, Milwaukee WI 53226 (E-mail: ejacobs@mcw.edu). $0022-5223 / \$ 36.00$

Copyright (c) 2011 by The American Association for Thoracic Surgery doi:10.1016/j.jtcvs.2010.07.007
}

chose the time frame of 48 hours because changes in protein expression potentially related to differences in vasoactivity should reasonably be expected by this time, and pilot experiments supported changes in vascular reactivity within 2 days.

Our experiments demonstrated enhanced endotheliumdependent reactivity of pulmonary arteries contralateral to the shunt ${ }^{4}$ relative to that of control and ipsilateral pulmonary arteries. We hypothesized that either decreased synthesis of a vasodilatory product or enhanced release of a constrictor from right (contralateral) pulmonary arteries would account for this difference in reactivity to thromboxane agonists. Because nitric oxide (NO) and metabolites of arachidonic acid are known to modulate pulmonary vascular tone, we blocked the synthesis of these products to test the contribution of these mediators to enhanced constriction of unshunted pulmonary arteries.

\section{METHODS AND MATERIALS \\ Materials}

The following materials were used: nordihydroguaiaretic acid (NDGA) (N-5023; Sigma-Aldrich, St Louis, Mo); indomethacin (I-7378, SigmaAldrich), L-N ${ }^{\mathrm{g}}$-monomethylarginine (L -NMMA, ALX-106-001-M025; Axxora, LLC, San Diego, Calif); cinnamyl-3,4-dihydroxy- $\alpha$-cyanocinnamate (CDC) (EI211-0010, Biomol International, LP, Plymouth Meeting, Pa); U46619 (PG-023; Biomol International); A23187 (C7522, Sigma-Aldrich); 


$$
\begin{aligned}
& \text { Abbreviations and Acronyms } \\
& \begin{aligned}
\mathrm{Ab} & =\text { antibody } \\
\mathrm{CDC} & =\text { cyanocinnamate } \\
\mathrm{CYP} & =\text { cytochrome P450 } \\
\mathrm{DDMS} & =\text { dibromo-dodecynyl-methylsulfimide } \\
\text { eNOS } & =\text { endothelial nitric oxide synthase } \\
\mathrm{HEPES} & =\text { N-2-hydroxyethylpiperazine-N'-2- } \\
& \text { ethanesulfonic acid } \\
\mathrm{HETA} & =12 \text {-hydroxyeicosatrienoic acid } \\
\mathrm{IC} & =\text { inhibitory concentration of } 50 \% \\
\text { L-NMMA } & =\text { L - } \mathrm{N}^{\mathrm{g}} \text {-monomethylarginine } \\
\text { LOX } & =\text { lipoxygenase } \\
\text { NDGA } & =\text { nordihydroguaiaretic acid } \\
\text { PG } & =\text { prostaglandin } \\
\text { THETA } & =\text { trihydroxyeicosatrienoic acid }
\end{aligned}
\end{aligned}
$$

5-lipoxygenase (LOX) antibody (5-LOX Ab; 160402; Cayman Chemical, Ann Arbor, Mich); 12-LOX Ab (160304; Cayman Chemical); 15-LOX1 Ab (H-235: sc-32940; Santa Cruz Biotechnology, Inc, Santa Cruz, Calif); and 15-LOX2 Ab (H-55: sc-67142; Santa Cruz Biotechnology, Inc); endothelial nitric oxide synthase (eNOS) Ab (sc-7271, Santa Cruz Biotechnology, Inc); beta actin Ab (Sigma A2228); arachidonic acid (56028; Nuchek Prep, Inc, Elysian, Minn); $\left[{ }^{14} \mathrm{C}(\mathrm{U})\right]$-arachidonic acid (specific activity $920 \mathrm{mCi} /$ mmol) (NEN Radiochemcials, Perkin Elmer, Waltham, Mass); ECL Plus detection reagent (RPN 2133, Amersham Biosciences, Piscataway, NJ).

\section{Surgical Anastomosis}

For details of this procedure, see our companion paper and our previous publication. ${ }^{5}$ All animals received care in compliance with the " Guide for the Care and Use of Laboratory Animals" published by the National Institutes of Health. A thoracotomy was performed and the left lower lobe pulmonary artery ligated proximally. The distal left lower lobe pulmonary artery was sewn end to side to the descending thoracic aorta. Measurements of flow through the shunt were obtained immediately before and after creation of the shunt as well as at the time of harvest. "High flow" was defined as flow rates through the anastomoses at harvest that were either twice that of the right lower lobe pulmonary artery or twice that of the left lower lobe pulmonary artery before the anastomosis. In some animals, low-flow shunts were deliberately created by anastomosing the left lower lobe pulmonary artery to an opening created by a 3-mm instead of a 5-mm aortic punch. Harvest flows less than half that of the unshunted right lower lobe pulmonary artery or the left lower lobe pulmonary artery before shunt creation we defined as "low flow."

\section{Harvesting Lungs, Dissecting Pulmonary Arteries}

Two days after the creation of the anastomosis, pigs were sedated and intubated. A thoracotomy was performed and flow rates of the anastomosed left pulmonary arteries were determined. After flow measurements, animals were humanely killed through exsanguination under deep anesthesia. The heart and lungs were removed en bloc and then transported on ice to the laboratory where pulmonary arteries 1 to $2 \mathrm{~mm}$ in diameter were dissected microscopically for studies.

\section{Ring Tension Studies}

Tension measurements were obtained according to methods previously published by us. ${ }^{6}$ Pulmonary artery rings, microdissected free of adherent lung tissue and 1- to 2-mm in diameter, were held in ice-cold physiologic saline solution (in mmol/L: $\mathrm{NaCl} 130, \mathrm{CaCl}_{2} 2.5 ; \mathrm{NaHCO}_{3} 15 ; \mathrm{MgSO}_{4}$ 1.2; $\mathrm{NaH}_{2} \mathrm{PO}_{4}$ 1.2; $\mathrm{KCl}$ 4.7; glucose 5.5; HEPES (N-2-hydroxyethylpiperazine-N'-2-ethanesulfonic acid) 10 ; and ethylenediaminetetraacetic acid 0.026; $\mathrm{pH} 7.4$ ) until use. Rings were mounted on tungsten wires connected to a force displacement transducer (model FT03E; Grass Instruments, West Warwick, RI) for continuously measuring isometric tension. The apparatus was immersed in $\mathrm{pH}$-adjusted, oxygenated physiologic saline solution (95\% oxygen and $5 \%$ carbon dioxide) at $37^{\circ} \mathrm{C}$. Rings from shunted and unshunted lobes were preloaded with $0.4 \mathrm{~g}$ of passive tension to maximize active tension development and then equilibrated for an additional $30 \mathrm{~min}-$ utes before the studies began. Concentration responses to the thromboxane mimetic U-46619 (eg, reference 5), an established pulmonary artery vasoconstrictor, were used to determine the tone of the pulmonary artery rings.

\section{Western Analysis}

Western analyses were performed according to our previously published methods. ${ }^{6}$ Protein determination in crude homogenates of pulmonary arteries 1- to 3-mm in diameter was estimated using a Bio-Rad protein assay kit (Bio-Rad Laboratories, Berkeley, Calif). Specific antibodies for 5-LOX, 12-LOX, 15-LOX1, 15-LOX2, or eNOS were matched with secondary antibodies and visualized with ECL Plus detection reagent. Blots were also probed for actin to normalize for protein loading. The blots were scanned using an Alpha Image 220 Analysis System (Alpha Innotech Corporation, San Leandro, Calif), and the relative densities of the bands from the same blot were compared.

Metabolism of $\left[{ }^{14} \mathrm{C}\right]$-arachidonic acid in ex vivo pulmonary arteries. These studies were completed using methods previously published by us. ${ }^{7}$ Pulmonary arteries $1-$ to $3-\mathrm{mm}$ in diameter were dissected, cleaned, and cut into 2- to 3-mm rings in HEPES buffer (mmol/L): 10 HEPES, $150 \mathrm{NaCl}, 5 \mathrm{KCl}, 2 \mathrm{CaCl}_{2}, 1 \mathrm{MgCl}_{2}, 6$ glucose, $\mathrm{pH}$ 7.4. Rings were incubated at $37^{\circ} \mathrm{C}$ in $5 \mathrm{~mL}$ HEPES with $\left[{ }^{14} \mathrm{C}\right]$-arachidonic acid $\left(0.5 \mu \mathrm{Ci}, 10^{-7} \mathrm{~mol} / \mathrm{L}\right)$. After 5 minutes, A23187 $\left(10^{-5} \mathrm{~mol} / \mathrm{L}\right)$ was added. The reaction was stopped after 10 minutes with ethanol $(15 \%$ final concentration), and the samples were extracted using Bond Elut C18 octadecylsilyl columns (Varian, Inc, San Carlos, Calif). The extracts were analyzed by reverse phase high-performancy liquid chromatography using a Nucleosil C18 $(5 \mu, 4.6 \times 250 \mathrm{~mm})$ column (Varian, Inc). The solvent system consisted of a 40-minute linear gradient (flow rate $=1 \mathrm{~mL} / \mathrm{min}$ ) from $50 \%$ solvent B (acetonitrile with $0.1 \%$ glacial acetic acid) in solvent A (deionized water) to $100 \%$ solvent $\mathrm{B}$. Column effluent was collected in $0.2-\mathrm{mL}$ fractions, and the radioactivity was determined. Identification of metabolites was based on elution times identical to that of authentic standards.

\section{Statistical Analyses}

Experimental results for individual test conditions from 4 to 5 rings from the left and an equal number from the right of a single host were averaged for each " $n$.", Therefore, the " $n$ "'s provided in the results section represent individual animals rather than individual pulmonary artery rings. Values are expressed as the means \pm standard errors. Comparisons between controls and treatments (or left vs right) were analyzed by 2-way repeated measures analysis of variance followed by post hoc tests when permitted. Values for paired studies (eg, left lower lobe pulmonary artery tension to a specific concentration of U46619 with and without CDC or NDGA) were compared by the $t$ test.

\section{RESULTS}

\section{Difference in Right and Left Pulmonary Artery Contractility to U-46619 Is Not Accounted for by NOS Activity or Expression}

Pulmonary arteries from the unshunted right lower lobes of high-flow pigs exhibited higher tension to U46619 than matched left pulmonary arteries distal to the shunt 48 hours 

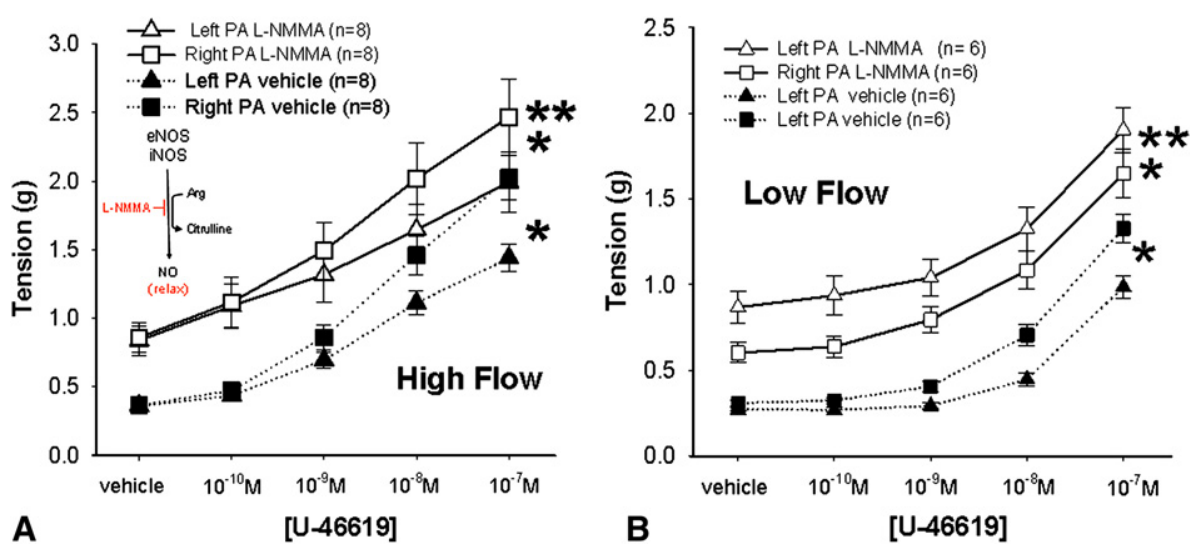

FIGURE 1. The inset schematic denotes the sources and effects of NO on pulmonary vascular tone and site of action of L-NMMA. Rings from high-flow pigs (A) or low-flow pigs (B) were treated with L-NMMA $\left(10^{-3} \mathrm{~mol} / \mathrm{L}\right)$ or vehicle, allowed to equilibrate for 30 minutes, and then a concentration response to U46619 was obtained. See legends for identification of treatment groups. Single asterisks denote concentration curves of left and right pulmonary arteries that are different one from the other based on 2 -way repeated measures analysis of variance $(P<.05)$. Double asterisks indicate differences in response curves of pulmonary arteries treated with L-NMMA relative to that of pulmonary arteries treated with vehicle. L-NMMA increased basal tension and shifted the concentration response to U46619 of all pulmonary arteries up and to the left, regardless of the flow state of the shunt. PA, Pulmonary artery; L-NMMA, L-N ${ }^{\mathrm{g}}$ monomethylarginine; eNOS, endothelial nitric oxide synthase; iNOS, inducible nitric oxide synthase.

after anastomosis, whereas the opposite relationship was true in pulmonary arteries from low-flow hosts (Figure 1). We tested the contribution of NOS to differential reactivity by treatment 30 minutes before constriction with U46619 with the L-arginine analog L-NMMA $\left(10^{-3} \mathrm{~mol} / \mathrm{L}\right)$, which stereospecifically inhibits NOS. ${ }^{8}$ L-NMMA increased baseline- and U46619-generated tension in rings from both the left and right lower lobe pulmonary arteries derived from either high- or low-flow hosts (Figure 1, $A$ and $B$ ). Although inhibition of NOS lessened, it did not eliminate the difference in tension between left and right pulmonary arteries of high- or low-flow hosts.

There was no difference in expression of eNOS protein in matched pulmonary arteries from left relative to right lower lobes of either high-flow or low-flow hosts (Figure 2). There were also no differences in eNOS protein density in highflow relative to low-flow hosts.

\section{Inhibition of Arachidonic Acid Metabolites Decreased Contractility Induced by High Flow}

See Figure 3, A, for a schematic of major arachidonic acid metabolites, their vasoactive effects on pulmonary arteries, and the site of action of inhibitors. Contractility to U46619 in left and right lower lobe pulmonary arteries from highflow hosts was examined in the presence of a cocktail containing inhibitors of the 3 enzymes that metabolize arachidonic acids to vasoactive derivatives versus vehicle. The cocktail contained (1) the COX inhibitor indomethacin (100 $\mu \mathrm{mol} / \mathrm{L})$ to block COX-1 and $2,{ }^{9}$ (2) the cytochrome P450 (CYP) inhibitor dibromo-dodecynyl-methylsulfimide (DDMS), $20 \mu \mathrm{mol} / \mathrm{L},{ }^{10}$ and (3) the LOX inhibitor NDGA $(20 \mu \mathrm{mol} / \mathrm{L}) .{ }^{11}$ In the presence of the cocktail, the pulmonary arteries from both the right and left (shunted) lobes of the lung of high-flow hosts constricted to the same extent to U46619 (Figure 3,B). Next, each inhibitor was tested individually (Figure 3, $C$ and $D$ ).
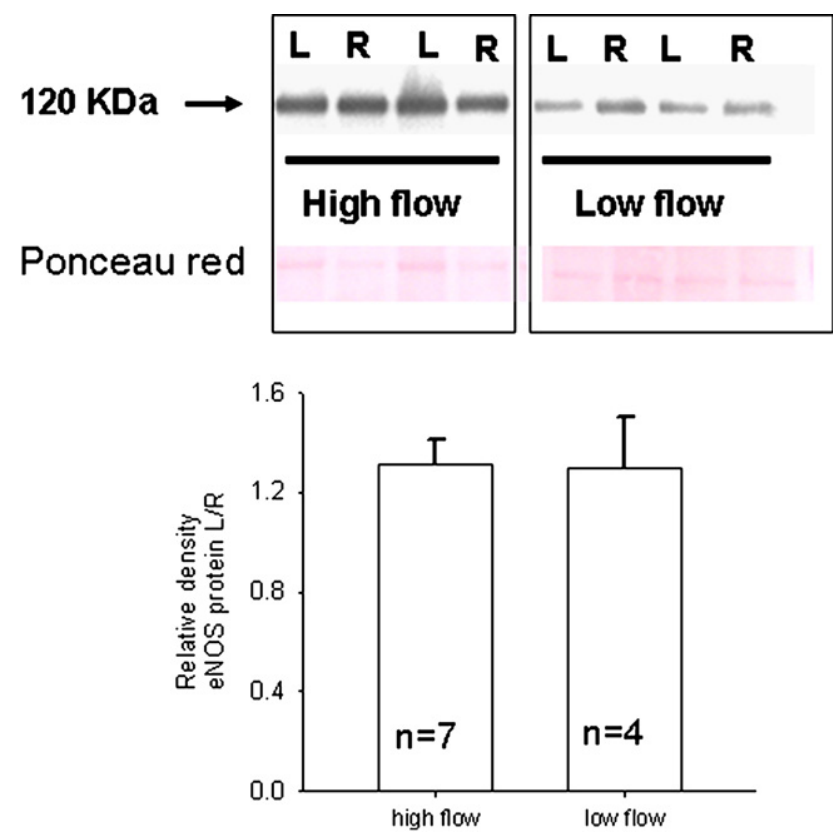

FIGURE 2. Western blots for detection of eNOS immunospecific protein in homogenized pulmonary artery vessels from left or right lower lobe of 7 high-flow pigs and 4 low-flow pigs were performed. Representative examples of images from these studies appear in part A. Ponceau red (below the eNOS Westerns) was used to correct for loading of protein. Ratios of densities of $\mathrm{L} / \mathrm{R}$ eNOS bands from the same Western blots appear in part B. There were no differences in eNOS protein expression in left and right lower lobe pulmonary arteries in samples obtained from either high- or low-flow pigs. $e N O S$, Endothelial nitric oxide synthase; $L / R$, left/right. 


\section{AA metabolism \& inhibitors}
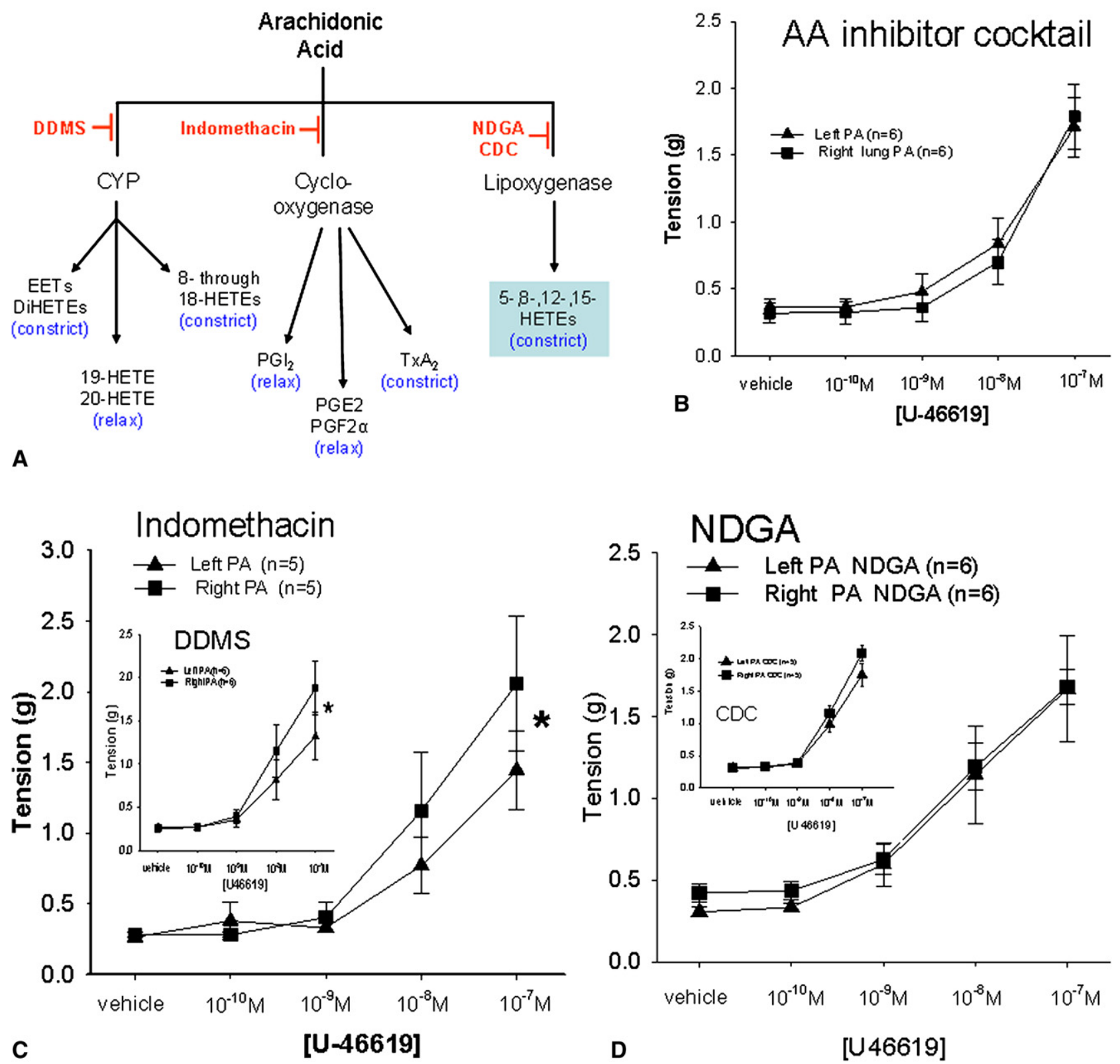

C

[U-46619]

[U46619]

FIGURE 3. A, This schematic depicts 3 major pathways of arachidonic acid metabolism, the dominant vasoactive effects of metabolites of this pathway, and the site of action of inhibitors we used in these experiments. The blue box shows products that are (1) blocked by NDGA and CDC, (2) reported to increase the tone of pulmonary arteries, and (3) synthesized in increased amounts by right pulmonary arteries contralateral to systemic pulmonary shunts (see Figure 5). B, U46619 concentration response curves of pulmonary arteries from high-flow pigs treated with vehicle or an inhibitor cocktail that included indomethacin $(100 \mu \mathrm{mol} / \mathrm{L})$, DDMS $(20 \mu \mathrm{mol} / \mathrm{L})$, and NDGA $(20 \mu \mathrm{mol} / \mathrm{L})$ for 30 minutes were obtained. The concentration response curves of left and right lower lobe pulmonary arteries after treatment with the cocktail of inhibitors were not different $(\mathrm{n}=6 ; P>.5$, 2-way repeated measures analysis of variance). $\mathrm{C}$, Treatment with indomethacin $(100 \mu \mathrm{mol} / \mathrm{L})$ or DDMS $(20 \mu \mathrm{mol} / \mathrm{L}$; inset $)$ did not eliminate the differences in contractility of right and left lower lobe pulmonary arteries to $\mathrm{U} 46619$ ( $\mathrm{n}=5 ; P<.05$ by 2 -way repeated measures analysis of variance). D, Treatment with NDGA $(20 \mu \mathrm{mol} / \mathrm{L})$ or CDC $(10 \mu \mathrm{mol} / \mathrm{L}$; inset) eliminated the differences between reactivity of left and right lower lobe pulmonary arteries to U46619 ( $n=6$ each). Contraction of left lower lobe pulmonary arteries was unaffected by NDGA treatment relative to controls, whereas reactivity of the right lower lobe pulmonary arteries was significantly decreased by this inhibitor ( $\mathrm{n}=6 ; P<.05$ by analysis of variance). $A A$, Arachidonic acid; $P A$, pulmonary artery; $D D M S$, dibromo-dodecynylmethylsulfimide; $N D G A$, nordihydroguaiaretic acid; $C D C$, cyanocinnamate; $C Y P$, cytochrome P450; HETE, 12-hydroxyeicosatrienoic acid; $E E T$, epoxyeicosatrienoic acids; $P G$, prostaglandin; $T x A_{2}$, thromboxane $\mathrm{A}_{2} ; N D G A$, nordihydroguaiaretic acid. 

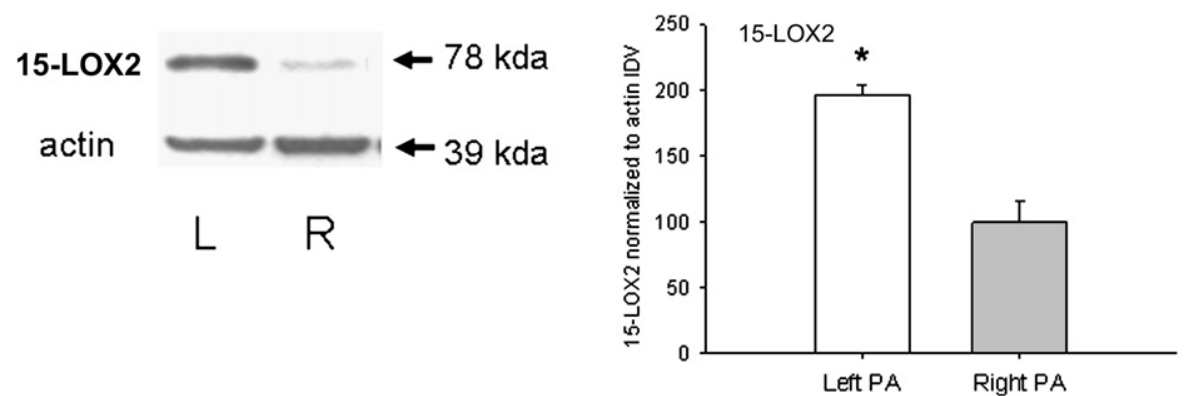

FIGURE 4. Western blots for 15-LOX2 were performed on homogenates of microdissected pulmonary arteries from left and right lower lobe pulmonary arteries, and densities of immunospecific bands for these proteins and beta actin were compared $(\mathrm{n}=6$ samples from left and right lower lobe pulmonary arteries each). The ratio of actin-normalized 15-LOX2 protein density was higher in left than right pulmonary artery homogenates by a factor of roughly $2(P<.05 ; \mathrm{n}=6)$. LOX, Lipoxygenase; $I D V$, independent diversity values. $* P<.05$ left relative to right.

\section{Decreased Contractility Induced by High Flow Is Not Mediated by Differences in COX or CYP Activity}

Pulmonary artery rings were treated with indomethacin (COX inhibitor) or DDMS (CYP inhibitor) alone and then contracted with U46619 $\left(10^{-10}-10^{-7} \mathrm{~mol} / \mathrm{L}\right)$. Higher tensions in high-flow pulmonary arteries from the right lower lobe were still observed (Figure 3,C). Thus, although COX or CYP may contribute some to the differences in contractility of shunted and nonshunted pulmonary arteries, these metabolites do not appear to have a large effect on this end point.

\section{Changes in Contractility Induced by High Flow Are Mediated by Changes in LOXs}

A third inhibitor in the cocktail, NDGA $(10 \mu \mathrm{mol} / \mathrm{L}$, Figure $3, D$ ), substantially eliminated the difference in contraction between shunted and control lung pulmonary arteries. Similarly, a second LOX inhibitor, CDC (10 $\mu \mathrm{mol} / \mathrm{L}$; Figure $3, D$, inset), eliminated the difference between contraction of left and right pulmonary arteries from high-flow hosts as well.

Western blots of pulmonary artery homogenates from left and right lower lobes of high-flow hosts were probed with primary antibodies for 5-LOX, 12-LOX, 15-LOX1, and 15-LOX2. Expression of 5- and 12-LOX as well as 15LOX1 was not different between samples from left and right lower lobe vessels (data not shown). The density of 15-LOX2 was increased in left pulmonary arteries over that of right pulmonary arteries from high-flow hosts (Figure 4).

\section{${ }^{14} \mathrm{C}$ Metabolites of Arachidonic Acids}

We next investigated arachidonic acid metabolism of microdissected pulmonary arteries. Several products were identified on the basis of elution profiles in control as well as pulmonary arteries from high-flow hosts. The major products corresponded to 6-keto prostaglandin (PG) $\mathrm{F}_{1 \alpha}$, 11,12,15-trihydroxyeicosatrienoic acids (THETAs), 12HETE and 15-HETE (see representative chromatograms, Figure 5). The arachidonic acid metabolite profile of control left and right pulmonary arteries was identical (not shown). Compared with synthetic capacity of control pulmonary arteries, both right and left pulmonary arteries from high-flow hosts exhibited increased prostanoid products, including peaks that correspond to 6-keto-PGF $1 \alpha$.

In examining high-performance liquid chromatography products of right and left pulmonary arteries from highflow hosts, we observed other differences in metabolites. Right pulmonary arteries from high-flow hosts produced more 12-HETE $(P<.05)$ than control right or left pulmonary arteries $(10.5 \pm 1.3,6.7 \pm 0.7$ and $6.5 \pm 0.9 \mathrm{cmp} / \mathrm{mg}$ protein, respectively ( $\mathrm{n}=5$ each). Synthesis of this product was decreased by more than $80 \%$ in samples incubated with $10 \mu \mathrm{mol} / \mathrm{L}$ CDC compared with vehicle control. Enhanced synthesis of a product that comigrated with 15-HETE in 3 of 4 pairs in right compared with left pulmonary arteries was also observed, although this increase was not statistically significant. Inasmuch as 15- and 12-HETEs increase the tension in pulmonary arteries, ${ }^{6,12}$ enhanced HETE synthesis in unshunted right pulmonary arteries is a good candidate to mediate increased tension to U46619.

\section{DISCUSSION}

We have observed endothelium-dependent enhanced reactivity of pulmonary arteries contralateral to a high-flow/highpressure shunt 48 hours after creation of a localized anastomosis (Figure 1, A). Therefore, the investigations in this article focused on identification of endothelium-derived contracting factors that were overexpressed or prodilatory factors that were decreased in unshunted relative to shunted pulmonary arteries in this model. In this regard, several endotheliumderived products including NO, prostacyclin, and 20-HETE are reported to cause vasorelaxation in the pulmonary circulation. ${ }^{3,13,14}$ Of these products, both prostacyclin and NO are augmented by exposure to high flow. ${ }^{15,16}$ Similarly, endothelium-derived epoxyeicosatrienoic acids, endothelin1, thromboxane, and LOX products, have pulmonary vasoconstrictive properties. ${ }^{6,17,18}$ Our studies show for the first time that enhanced constriction of unshunted pulmonary 


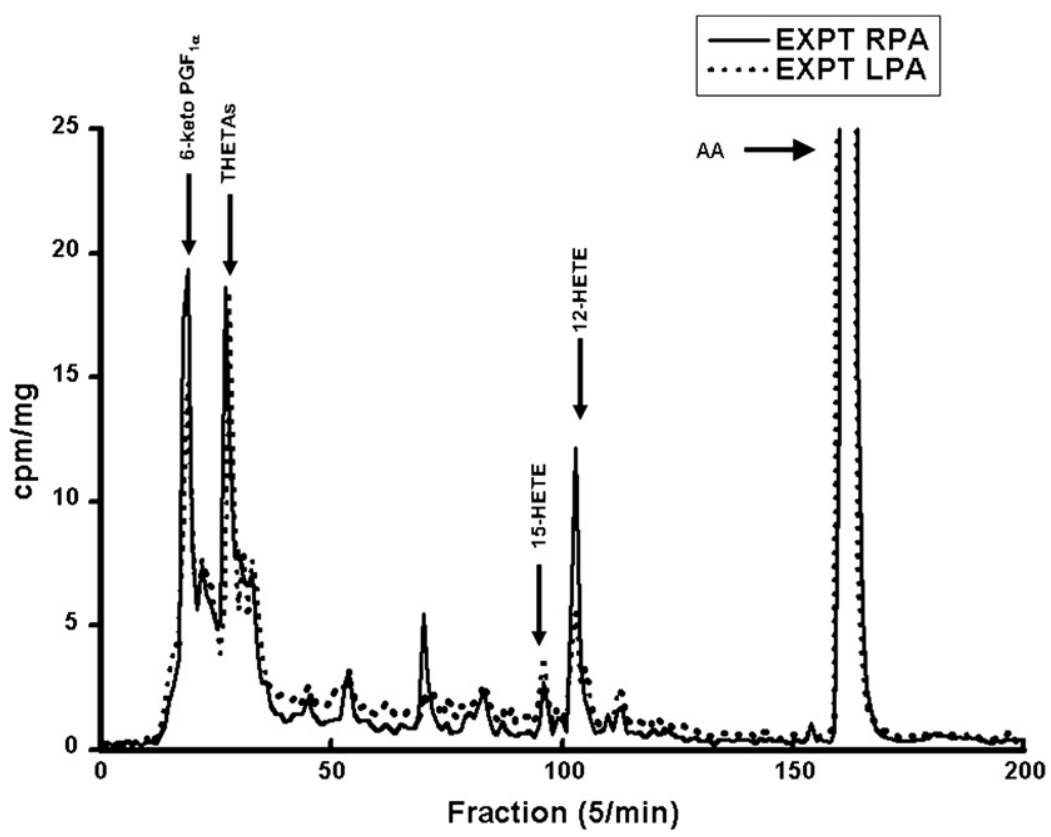

FIGURE 5. Arachidonic acid metabolism in isolated pulmonary artery segments. A representative chromatogram from a pair of shunted and unshunted pulmonary arteries of high-flow pigs (see legend for identification code) is shown. Migration times of known standards are indicated. Results were normalized to vessel weight and expressed as cpm/mg. A peak that elutes at 20 to 21 minutes (fractions 100-105) coincident with authentic 12-HETE is higher in the right pulmonary artery sample. AA, Arachidonic acid; HETA, hydroxyeicosatrienoic acid; RPA, right pulmonary artery; $L P A$, left pulmonary artery.

arteries to U46619 relative to that of control pulmonary arteries or those distal to the anastomosis is eliminated by 2 different inhibitors of the LOX pathway, but not by inhibitors of COX, CYP, or NOS. Coupled with evidence of increased synthesis of LOX products in unshunted pulmonary arteries over that of controls, these data suggest a role for enhanced production of vasoconstrictive LOX products in promoting a proconstrictive state in these arteries. We believe our data are also the first to demonstrate flow-induced changes in products of small arteries remote (in fact contralateral) to a localized shunt and differences in reactivity based on these differences in metabolite production.

Increased contractility of right lower lobe pulmonary arteries in our high-flow model was not attributable entirely to a decrease in eNOS activity because after inhibition of NOS by L-NMMA, the right remained significantly more reactive than the left. Similarly, eNOS-immunospecific protein was not different in left and right lower lobe pulmonary arteries 48 hours after anastomosis. These observations do not exclude flow-induced alterations in eNOS expression or activity before or after 48 hours or eNOS uncoupling in contribution to enhanced constriction in unshunted pulmonary arteries. ${ }^{1}$ In fact, eNOS uncoupling may well occur in pulmonary arteries distal to the shunt, but be masked by either enhanced eNOS expression or upregulation of some other mediator that balances the effects of eNOS uncoupling.

On the other hand, a cocktail that included inhibitors of all 3 major pathways of arachidonic acid metabolism elimi- nated the differences in the U46619 response curve of right and left lower lobe pulmonary arteries. When these inhibitors were tested individually, only the LOX inhibitors NDGA or CDC decreased response of right lower lobe pulmonary arteries to U46619 to that of their left lower lobe counterparts. NDGA is a LOX inhibitor with activity against cysteinyl-leukotriene synthesis with $50 \%$ inhibitory concentrations less than $10 \mu \mathrm{mol} / \mathrm{L}$ for 5-, 12- and 15-LOX in human pulmonary artery endothelial cells. ${ }^{19}$ Similarly, $\mathrm{CDC}$ has $\mathrm{IC}_{50}$ less than $3 \mu \mathrm{mol} / \mathrm{L}$ for 5-, 12-, and 15 - in isolated enzyme preparations. ${ }^{20}$ Thus the concentrations of both NDGA and CDC used in these investigations should have effectively inhibited cysteinyl-leukotriene synthesis from all 3 isoforms in the ex vivo pulmonary arteries.

To evaluate the potential contribution of differential expression of LOX to the reactivity profile, we performed Western blots of homogenates of microdissected pulmonary arteries probed with antibodies to 5-LOX, 12-LOX, 15-LOX1, and 15-LOX2. We observed no differences in density of 5-, $12-$, or 15-LOX1, but an increase in 15-LOX2 expression in shunted left over right pulmonary arteries. In humans, 15LOX1 and 15-LOX2 are derived from 2 different genes. ${ }^{21,22}$ The enzymes display tissue- and cell-specific expression patterns. The dissimilar expression of isoform-specific 15-LOXs in these investigations may relate to differences in reactivity of shunted and nonshunted pulmonary arteries, but further studies are necessary to confirm this observation.

We also examined eicosanoid metabolism in ex vivo pulmonary arteries. Our data demonstrate enhanced production 
of 12-HETE in hypercontractile pulmonary arteries contralateral to localized shunts. LOX products are known to mediate vasoreactive responses in the lung. Inhibition of 5-LOX-activating protein reduces pulmonary vascular reactivity and hypertension in hypoxic rats, and mice bred with the deletion of 5-LOX developed less right heart hypertrophy to hypoxia than their matched wild-type counterparts. ${ }^{23}$ Similarly 15-HETE, a product of 15-LOX, causes concentration-dependent contraction of pulmonary artery rings in rabbit kits exposed to hypoxia. ${ }^{6} \mathrm{CDC}$ blocks the increased reactivity of right over left pulmonary arteries and decreases the synthesis of 12-HETE. Together, our data position enhanced production of 12- or 15-HETE derived from pulmonary arteries contralateral to a localized shunt as a good candidate for mediating increased reactivity of these arteries. They do not exclude potential contributions of other systems that modulate pulmonary vascular tone, such as endothelin.

In summary, we demonstrated increased reactivity of unshunted right over shunted left pulmonary arteries eliminated by LOX inhibitors NDGA and CDC and enhanced production of LOX product 12-HETE in these same pulmonary arteries with enhanced reactivity. These unexpected findings may have clinical implications in conditions such as traumatic or naturally occurring systemic-pulmonary artery fistula ${ }^{24}$ or increased global pulmonary vascular resistance in conditions of isolated aortic origin of the right pulmonary artery. ${ }^{25}$ In addition to primary effects of high flow on shunted pulmonary arteries, our studies suggest that careful investigations of flow effects on eicosanoid synthesis of pulmonary arteries remote and distal to localized shunts should be undertaken. Eicosanoid products of pulmonary arteries contralateral to a localized shunt may contribute to enhanced generalized pulmonary vascular resistance.

We acknowledge the significant contributions of Drs Bousamra, Nirula, Friesema, and Zhu, as well as Stephanie Gruenloh to the works in this communication.

\section{References}

1. Farrow KN, Lakshminrusimha S, Reda WJ, Wedgwood S, Czech L, Gugino SF, et al. Superoxide dismutase restores eNOS expression and function in resistance pulmonary arteries from neonatal lambs with persistent pulmonary hypertension. Am J Physiol Lung Cell Mol Physiol. 2008;295:L979-87.

2. Storme L, Rairigh RL, Parker TA, Kinsella JP, Abman SH. Acute intrauterine pulmonary hypertension impairs endothelium-dependent vasodilation in the ovine fetus. Pediatr Res. 1999;45(4 Pt 1):575-81.

3. Black SM, Fineman JR, Steinhorn RH, Bristow J, Soifer SJ. Increased endothelial NOS in lambs with increased pulmonary blood flow and pulmonary hypertension. Am J Physiol. 1998;275(5 Pt 2):H1643-51.

4. Somberg L, Nirula R, Bousamra M II, Friesema J, Zhu D, Medhora M, et al. Effects of a localized high-flow anastomosis between aorta and left lower lobe pulmonary artery on flow and pulmonary vascular reactivity. $J$ Thorac Cardiovasc Surg. 2011;141:407-12.
5. Bousamra M 2nd, Rossi R, Jacobs E, Parviz M, Busch C, Nelin LD, et al. Systemic lobar shunting induces advanced pulmonary vasculopathy. $J$ Thorac Cardiovasc Surg. 2000;120:88-98.

6. Zhu D, Medhora M, Campbell WB, Spitzbarth N, Baker JE, Jacobs ER. Chronic hypoxia activates lung 15-lipoxygenase, which catalyzes production of 15-HETE and enhances constriction in neonatal rabbit pulmonary arteries. Circ Res. 2003; 92:992-1000.

7. Chawengsub Y, Aggarwal NT, Nithipatikom K, Gauthier KM, Anjaiah S, Hammock BD, et al. Identification of 15-hydroxy-11,12-epoxyeicosatrienoic acid as a vasoactive 15-lipoxygenase metabolite in rabbit aorta. Am J Physiol Heart Circ Physiol. 2008;294:H1348-56.

8. Jovanovic A, Grbovic L, Tulic I. Predominant role for nitric oxide in the relaxation induced by acetylcholine in human uterine artery. Hum Reprod. 1994;9: 387-93.

9. Dannhardt G, Ulbrich H. In-vitro test system for the evaluation of cyclooxygenase-1 (COX-1) and cyclooxygenase-2 (COX-2) inhibitors based on a single HPLC run with UV detection using bovine aortic coronary endothelial cells (BAECs). Inflamm Res. 2001;50:262-9.

10. Wang MH, Brand-Schieber E, Zand BA, Nguyen X, Falck JR, Balu N, et al. Cytochrome P450-derived arachidonic acid metabolism in the rat kidney: characterization of selective inhibitors. J Pharmacol Exp Ther. 1998;284:966-73.

11. Walker JL, Loscalzo J, Zhang YY. 5-Lipoxygenase and human pulmonary artery endothelial cell proliferation. Am J Physiol Heart Circ Physiol. 2002;282: H585-93.

12. Guo L, Tang X, Tian H, Liu Y, Wang Z, Wu H, et al. Subacute hypoxia suppresses Kv3.4 channel expression and whole-cell $\mathrm{K}+$ currents through endogenous 15hydroxyeicosatetraenoic acid in pulmonary arterial smooth muscle cells. Eur J Pharmacol. 2008;587:187-95.

13. Kadowitz PJ, Chapnick BM, Feigen LP, Hyman AL, Nelson PK, Spannhake EW Pulmonary and systemic vasodilator effects of the newly discovered prostaglandin, PGI2. J Appl Physiol. 1978;45:408-13.

14. Birks EK, Bousamra M, Presberg K, Marsh JA, Effros RM, Jacobs ER. Human pulmonary arteries dilate to 20-HETE, an endogenous eicosanoid of lung tissue. Am J Physiol. 1997;272(5 Pt 1):L823-9.

15. Frangos JA, Eskin SG, McIntire LV, Ives CL. Flow effects on prostacyclin production by cultured human endothelial cells. Science. 1985;227:1477-9.

16. Braam B, de Roos R, Bluyssen H, Kemmeren P, Holstege F, Joles JA, et al. Nitric oxide-dependent and nitric oxide-independent transcriptional responses to high shear stress in endothelial cells. Hypertension. 2005;45:672-80.

17. Kirshbom PM, Page SO, Jacobs MT, Tsui SS, Bello E, Ungerleider RM, et al Cardiopulmonary bypass and circulatory arrest increase endothelin-1 production and receptor expression in the lung. J Thorac Cardiovasc Surg. 1997;113:777-83.

18. Chu X, Tang X, Guo L, Bao H, Zhang S, Zhang J, et al. Hypoxia suppresses KV1.5 channel expression through endogenous 15-HETE in rat pulmonary artery. Prostaglandins Other Lipid Mediat. 2009;88:42-50.

19. Kamitani H, Geller M, Eling T. Expression of 15-lipoxygenase by human colorectal carcinoma caco-2 cells during apoptosis and cell differentiation. J Biol Chem. 1998;273:21569-77.

20. Cho H, Ueda M, Tamaoka M, Hamaguchi M, Aisaka K, Kiso Y, et al. Novel caffeic acid derivatives: extremely potent inhibitors of 12-lipoxygenase. $\mathrm{J} \mathrm{Med}$ Chem. 1991;34:1503-5.

21. Sigal E, Grunberger D, Craik CS, Caughey GH, Nadel JA. Arachidonate 15lipoxygenase (omega-6 lipoxygenase) from human leukocytes. purification and structural homology to other mammalian lipoxygenases. J Biol Chem. 1988; 263:5328-32.

22. Brash AR, Boeglin WE, Chang MS. Discovery of a second 15S-lipoxygenase in humans. Proc Natl Acad Sci U S A. 1997;94:6148-52.

23. Voelkel NF, Tuder RM, Wade K, Hoper M, Lepley RA, Goulet JL, et al. Inhibition of 5-lipoxygenase-activating protein (FLAP) reduces pulmonary vascular reactivity and pulmonary hypertension in hypoxic rats. J Clin Invest. 1996;97: 2491-8.

24. Loebl EC, Platt MR, Mills LJ, Estrera AS. Pulmonary resection for a traumatic pulmonary arteriovenous fistula: case report. J Thorac Cardiovasc Surg. 1979; 77:674-6.

25. Agarwala B, Waldman JD, Loe WA, Ruschhaupt DG. Aortic origin of the RPA immediate resolution of severe pulmonary artery hypertension by surgical repair. Pediatr Cardiol. 1994;15:41-4. 